\title{
Fostering resilience-oriented thinking in engineering practice
}

Kristen MacAskill BEng (Hons), MEngM, MPhil, PhD Lecturer, Department of Engineering, University of Cambridge, Cambridge, UK (Orcid:0000-0001-5995-6777) (corresponding author: kam71@cam.ac.uk)

Francesca O'Hanlon MEng, MPhil, MRes

PhD candidate, Department of Engineering, University of Cambridge, Cambridge, UK
Peter Guthrie OBE, FREng, FICE, FCGI

Professor, Department of Engineering, University of Cambridge,

Cambridge, UK

Juliet Mian MEng (Hons), PhD, FICE

Technical Director, Resilience Shift, London, UK; Associate Director, Arup, London, UK

Round tables discussing the resilience of critical infrastructure systems held in the UK, the USA and New Zealand have provided insight into how organisations are changing the basis of planning and investment decisions to enhance resilience. The events convened stakeholders to explore how resilience is embraced in their sectors and to identify how to advance practice. The overarching premise was to convene a diverse group who would not typically have an opportunity to engage with each other, to share their perspectives on putting resilience thinking into practice. The round tables identified that early-adopting organisations are implementing approaches to decision making that embrace resilience thinking, but such approaches are not yet embedded in common practice across organisations that are responsible for planning and managing critical infrastructure. The findings emphasise that multi-agency coordination and collaboration is required to advance resilience thinking in professional practice and to move beyond traditional risk-based paradigms. Governance and policy interventions will help encourage cross-sector information sharing and enforce responsibility and transparency surrounding exposure to potential shocks and stresses. It is recommended that such interventions could expand on principles and practice in existing emergencymanagement efforts, on the basis that such efforts are founded on coordinating various groups.

\section{Introduction}

Moving towards resilience-based approaches for infrastructure planning and investment requires challenging how infrastructure is currently planned, designed, delivered and operated. Decisions need to be driven not just by the initial capital cost but also by how infrastructure best serves its communities and how it continues to perform when subject to various shocks and stresses.

A short series of round tables was held in the UK, the USA and New Zealand on the theme of infrastructure resilience. The main objective was to engage with senior professionals (covering roles in the government, industry and academia), who would not typically have an opportunity to engage with each other, to share their perspectives on putting resilience thinking into practice. The format allowed exploration of how infrastructure systems might be impacted by a range of possible shocks and stresses, how various decision makers would respond and what the consequential cascading effects of those decisions would be. The round tables provided the basis for cross-sector learning and collaboration, creating a more informed view on interdependency, what is missing in governance frameworks and standards and identifying measures for embedding resilient design into modern infrastructure systems. The purpose of this paper is to share how the round tables were convened and to frame insights provided from this process, within the wider context of advancing resilience thinking in engineering practice.

The round tables form part of the Resilience Shift programme of projects and initiatives. They took place in parallel with a number of other projects designed to equip practitioners with the tools and approaches that they need to put resilience into practice; understand what drives best practice through sector-specific research and through exploration of the role of policy and specific policy instruments; and pursue a common understanding of resilience within and between critical infrastructure sectors, working with sector experts and transferring learning between sectors and geographies (see the website of Resilience Shift (2020) for more details on outputs from these initiatives).

There is a moral obligation of the engineering profession to consider environmental impact and to account for how infrastructure decisions made today will impact on the livelihood of both current and future generations. Techniques employed to put this wider responsibility into practice are highly varied; they are often unsupported by incentives to implement. As Hargreaves et al. (2020) recently highlighted, practising engineers in consulting and construction are typically contracted to deliver projects and provide value to their organisation and the client; they can find it difficult to balance this with their wider obligation to society. Pushing the boundaries beyond this can prove challenging, but it is essential for the long-term well-being of communities and the planet.

This paper reports on the insights developed from the round-table process and to help advance the application of resilience thinking in developing and managing critical infrastructure systems. The discussion is grounded in existing theory and studies of engineering resilience, and the intention is to help advance the resilience agenda in professional practice. 


\section{Key considerations}

In this section, the authors reflect on advances in the application of resilience thinking to infrastructure development and challenges with respect to governance and policy for supporting the development of resilient infrastructure. This sets the context in which to review the insights from the round tables.

\subsection{Definition}

Resilience provides a perspective for decision making that, in essence, considers how decisions made today might influence the performance of infrastructure in the future. Existing reviews of definition (e.g. Alexander, 2013; Hosseini et al., 2016; Tanner et al., 2017) provide good coverage of the issues but have not led to a definitive consensus, with the implication that there is a need for acceptance that various perspectives emphasise different arguments. Generally, resilience refers to having the capacity to maintain function when exposed to shocks or stresses. Approaches to resilience thinking that embrace greater complexity emphasise that an iterative and experimental approach that allows for learning is required (Tanner et al., 2017). Hollnagel et al. (2006) highlight that irregular and 'unexampled' shocks and stresses need to be acknowledged when considering the possible outcomes of decisions, which is not necessarily promoted by traditional risk paradigms.

\subsection{State of the art: resilience in infrastructure decision making}

Resilience frames thinking on a presumption that future events will be unexpected, in contrast to traditional risk-based paradigms of infrastructure design. This was acknowledged by Park et al. (2013) in their 'perspective paper' 'Integrating risk and resilience approaches to catastrophe management in engineering systems', but the idea traces further back to the seminal work by Holling (1973) on ecological resilience. This reinforces the increasingly acknowledged inadequacy of design parameters such as a ' 1 -in100 ' annual exceedance probability for flooding, both in terms of limitations in ability to identify accurately the probability and in terms of increasing impact of such events that comes with urban population growth (discussed in e.g. the paper by Miller and Hutchins (2017)). Past disasters are, in part, attributable to a failure to acknowledge the plausibility of the more extreme scenarios, even when there was existing knowledge. For example, modelling completed in 2010 suggested that there would be less than NZ\$44 million (NZ\$1 = US\$0.600) of damage to underground infrastructure assets in $90 \%$ of scenarios for a 1-in-1000 year earthquake in Christchurch, New Zealand (Sole, 2011). This served as a baseline figure for exposure. The costs from the earthquakes in Christchurch in 2010 and 2011 greatly exceeded this, with damage estimates exceeding NZ\$2 billion.

Several other formative publications have advanced resilience theory in engineering. Among them is the conceptual framework by Bruneau et al. (2003) for defining the seismic resilience of communities. Their underlying goal was to enhance the ability of infrastructure to perform after an event to allow a community to return to a normal level of functioning. Their paper was intended to set the foundation for a coordinated research effort across disciplines and makes two key contributions to advancing the discussion. Firstly, the focus is on the community, but various dimensions are covered: technical, organisational, social and economic. Bruneau et al. (2003) also conceptualised resilience in terms of four quantitative measures or properties: robustness (strength of elements or systems to withstand stress), rapidity (ability to contain losses), resourcefulness (ability to identify problems, prioritise and mobilise) and redundancy (substitutability of elements or systems). They did not provide definitive means to quantify resilience, yet their concept had appeal and has been cited widely in the literature.

\subsection{Call for cross-disciplinary, multi-organisational responses}

A potential shortfall of the framing by Bruneau et al. (2003) is the emphasis placed on probabilities to understand risk. It is increasingly acknowledged that such an approach has limitations because it cannot be applied to a multi-hazard assessment for an all-hazard approach. This is a critical issue and requires balancing reliance on probabilistic risk metrics alongside more qualitative measures.

In response to this is the promotion of a multidisciplinary approach that is more accepting of expert judgement and qualitative measures. Park et al. (2013) criticise existing approaches to engineering system design that are based on quantifying known risks. They emphasise that '[e]ngineering systems must confront dynamic and unpredictable environments and estimates of likelihood are notoriously unreliable' (Park et al., 2013: p. 359). They highlight the necessity of various organisations, government agencies and stakeholder groups to coordinate - bringing together different levels of knowledge around the functioning of the engineered system and its connections to wider, complex systems. Hollnagel et al. (2006) view resilience from a dynamic perspective and suggest that it cannot be determined analytically but requires reliance on expert knowledge of the system, with consideration of the goals of the core business. Hasan and Foliente (2015) also take the position that due to the wide socio-economic impacts of disruptive events beyond the direct infrastructure impacts, a multidisciplinary group of decision makers need to understand collectively the potential cascading impacts of decisions. The Overseas Development Institute (Tanner et al., 2017) formed similar conclusions in their review of challenges for resilience policy.

\subsection{Practical challenges/shortfalls/limitations in policy levers}

Scenario development and modelling is supported as a means of reviewing different possible futures and the social value of infrastructure decisions made today (Green and Chmutina, 2019; Hargreaves et al., 2020). Practically, taking a more long-term approach presents a number of challenges; it requires extra 
resources to collate and model data and revised decision making procedures. Hasan and Foliente (2015) and O'Brien and MacAskill (2019) highlight that the lack of access to data is a current limitation to running models that account for future uncertainty and interdependencies. They also conclude that a range of modelling approaches has been developed but many are out of reach of those responsible for managing assets. Hosseini et al. (2016) call for the need for data-driven standards for resilient systems, but they also acknowledge the need to aggregate expert opinion alongside other measures.

A key challenge in pursuing changes in practice lies in accountability and responsibility. The engineering profession can observe advances in responding to climate change and consider how similar developments might be applied to other potential shocks and stresses. A fundamental basis of the corporate social responsibility agenda that has emerged in response to sustainability concerns is to create wider accountability of organisations to their stakeholders, beyond the short-term financial performance of the organisation. Over the past decade, there have been substantial advances in organisational disclosure to climate risk in particular. The rise of this reporting presents an example of how new practices can emerge from voluntary schemes to a global standard. On this, Andrew and Cortese (2013) provide a helpful review of this process through the emergence of the Climate Disclosure Standards Board.

\subsection{Summary}

This review has covered three key points.

- It establishes a general position on what resilience means in engineering practice.

- It highlights a need to move beyond established riskmanagement procedures to acknowledge uncertainty surrounding an all-hazard approach.

- It highlights support towards fostering communications between various organisations, government agencies and stakeholder groups to bring together different levels of knowledge around the functioning of the engineered system and its connections to wider systems.

\section{Methodology}

The round tables involved participants with a range of disciplinary backgrounds, encouraging inter- and cross-sector communication. This format provides a means for participants to engage in reflective and challenging discussions about their sectors and to explore how to engender change. The round tables gathered asset owners, council officers, health specialists, engineering design specialists, community leaders and academics, engaging 79 people across four events. Around 20 participants per round table were considered ideal for allowing for a diverse range of stakeholders while also giving the opportunity for every participant to contribute actively to the discussion (in reality, guest numbers excluding facilitators ranged from 16 to 25 ). The discussions require two half-days, ideally split overnight.
Each round table had a specific objective.

- A pilot was held in February 2018 to test the methodology.

- The London meeting in November 2018 concentrated on ports, their role in the logistics supply chain and their dependence on supporting infrastructure systems.

- A meeting in Berkeley in January 2019 (convened with the University of California) focused on city-scale modelling tools and approaches and their relevance and applicability for practitioners.

- A meeting in Christchurch in February 2019 (convened with the Christchurch City Council) created the chance to reflect on the experience of recovery following the earthquakes in 2010/ 2011 and particularly the lessons that can be drawn for improving the resilience of the infrastructure as the city and region plan for the future.

The pilot event involved group discussions on various shocks and stress scenarios to provide a basis for dialogue. However, the predeveloped conceptual scenarios tended to narrow thinking too quickly (this was observed in the pilot round table). The design of subsequent round tables was reviewed to place more emphasis on drawing out participant experience and their views on a range of shocks and stresses. The pilot also helped inform focus themes for subsequent events. The overall process for planning and implementing the round tables is described in Figure 1.

The facilitators held discussions with each participant in advance of the round table (where possible) to brief them and to help them prepare their contribution. A list of shocks and stresses was also developed to facilitate broad discussion. The list was modelled on the principle of the five overarching headings of the World Economic Forum's global risk review (economic, environmental, geopolitical, societal and technological), applied with a more regional focus with 20-25 shocks/stresses in total for each round table. The list (see Table 1 for an example) was used to capture collective views on threats posed by a range of potential shocks and stresses for the local participants. The emphasis was not on the traditional likelihood-impact matrix of a typical risk assessment, but the capacity of the region and the organisations represented to respond (as indicated in Figure 2). Note that 'respond' in this context does not just imply disaster response, but a wider capability to manage the threat.

The exercise did not prescribe the size of a possible shock or stress, and it was left to the participants to make an assumption about what might be possible. The goal was to acknowledge the deep uncertainty associated with trying to determine risk, and the failure of modern society to acknowledge the significance of lowprobability, irregular or unexampled events. It proved a useful means to provoke reflection and discussion over broad areas of agreement and limitations in knowledge (discussed in the next section). The intention was to move away from the comfort of a traditional risk assessment matrix, which downplays the need to consider high-impact, low-probability events. It is more 


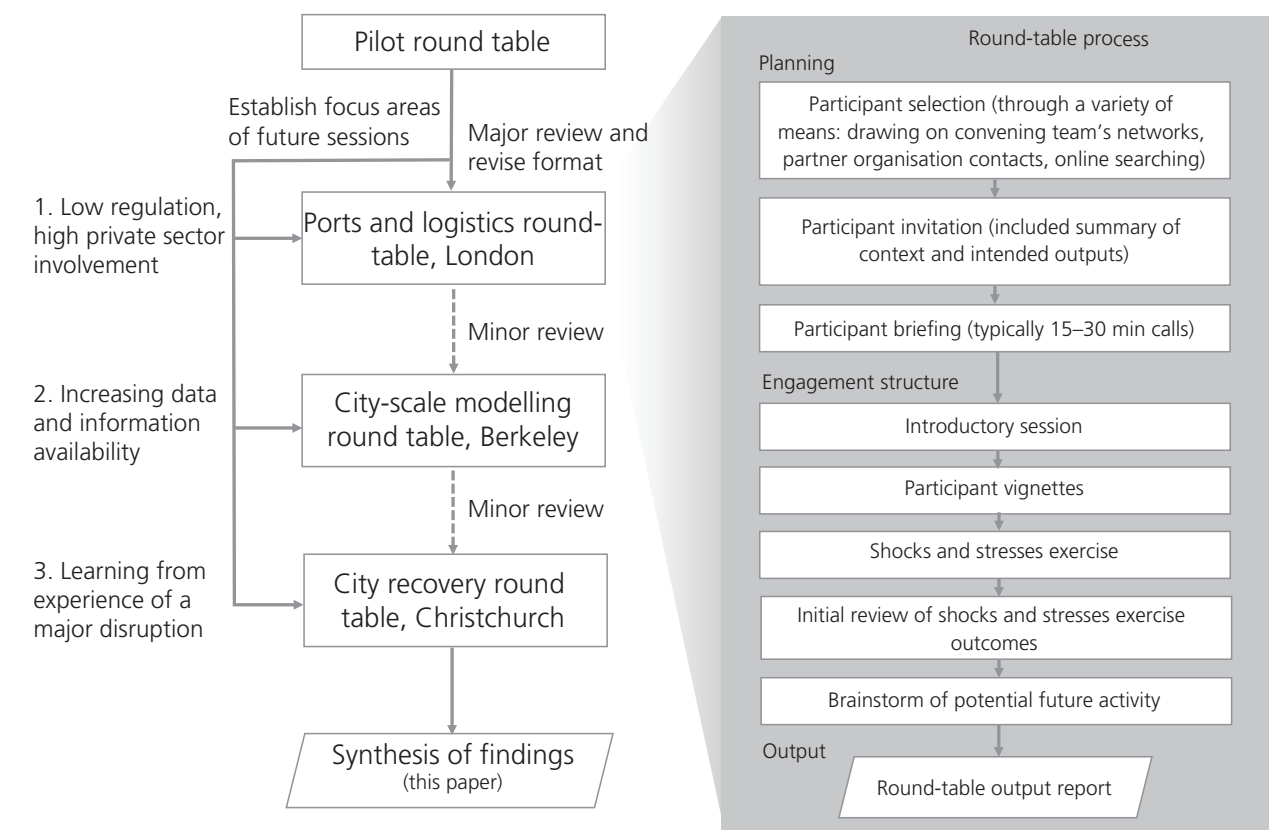

Figure 1. Round-table planning and implementation process

exploratory than other scenario techniques and could be seen as a precursor to adopting other methods such as the wildcard events described by Walsh et al. (2015). Other sessions involving short

Table 1. Example set of shocks/stresses

\begin{tabular}{ll} 
Type & \multicolumn{1}{c}{ Shock/stress description } \\
Economic/infrastructure & $\begin{array}{c}\text { Inadequate investment in power } \\
\text { infrastructure } \\
\text { Inadequate investment in rail } \\
\text { infrastructure } \\
\text { Inadequate investment in road } \\
\text { infrastructure } \\
\text { Inadequate investment in three water } \\
\text { infrastructures } \\
\text { Carbon dioxide pricing }\end{array}$ \\
Economic/geopolitical & Energy price shock \\
Environmental & Sustained adverse weather \\
& Local environmental event \\
Sea-level rise \\
Major natural hazard \\
Failure of international governance \\
Failure of national governance \\
Failure of regional or local governance \\
Fragmentation of service providers \\
Lack of access to information/data \\
Food crisis (changing balance of \\
imports/exports) \\
Water shortage \\
Labour - loss of institutional knowledge \\
Community disconnect with civic life \\
Critical information infrastructure \\
breakdown \\
Power failure \\
Data fraud or theft
\end{tabular}

presentations from participants to summarise their experience on applying resilience thinking also proved helpful in providing a basis for collective reflection. Figure 3 demonstrates some examples of the round-table set-up.

Group discussions were recorded to allow for later review and thematic analysis of the discussion. Participants were offered opportunities to provide feedback immediately following the events and on reports written to summarise the discussion (Resilience Shift, 2019a, 2019b, 2019c). Best efforts have been made to incorporate this feedback and to provide an unbiased account, but it must be acknowledged that not all participants took the opportunity to provide detailed feedback on the final output. The key themes identified helped shape the focus of the literature review presented in this paper. They are discussed in the next section with reference to specific examples and implications for advancement in practice.

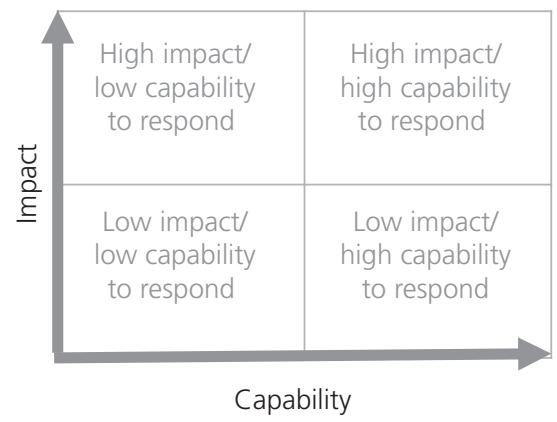

Figure 2. Impact/response capability matrix 


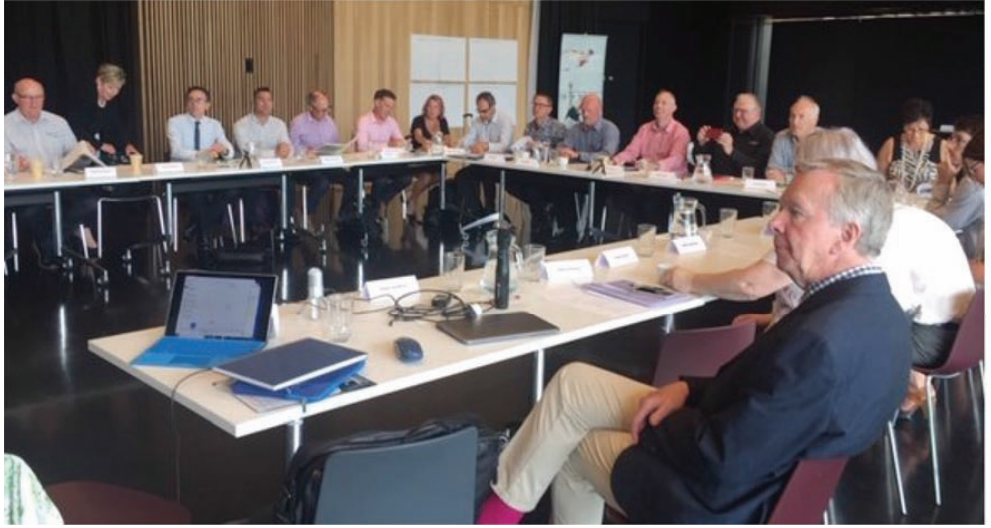

(a)

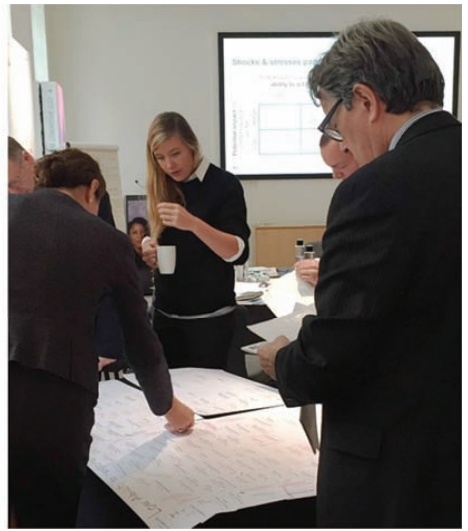

(b)

Figure 3. Examples of the event facilitation: (a) open round-table group; (b) shocks and stresses exercise

\section{Findings}

While each round table followed varied lines of discussion, some revealing insights emerged across themes of oversight, policy, relationships and information sharing.

\subsection{Organisational oversight}

Lack of strategic oversight is critical to address as a starting point. Dialogue across infrastructure operators and government agencies is crucial to developing shared understanding of resilience. Considering ports infrastructure from a national perspective in the UK provides an illustrative example. Lack of strategic oversight of ports inhibits coordinated response to major events. The constraints of commercial and political sensitivities identified in a prior study of the UK port sector (Shaw et al., 2017) were reinforced in the round-table discussion. Due to the privatised nature of the ports sector in the UK and the relatively light regulatory environment (compared with road, rail and water for instance), there is significant fragmentation when viewing operations from a national perspective. Port owners are understandably reluctant to share voluntarily information on the capacity and flexibility of their operations, given the competitive nature of the sector and commercial sensitivities. Additionally, while the ports themselves may be adapting for anticipated future demand, supporting road and rail networks are not necessarily developing at the same rate.

Elsewhere, early-adopting organisations have embedded resiliencebased principles into their asset management systems, such as reprioritising renewals based on a systemic view of asset criticality and vulnerability. See the paper by Barber and Golden (2012) and Davis (2015) for background commentary on examples that participants raised at the round tables. Determining asset criticality is not a new idea in asset management, but asset managers in the Berkeley and Christchurch round tables highlighted that augmenting this approach with an assessment of natural hazard exposure is not yet standard practice. Given the nascent nature of resilience practice, an idea that resonated with participants in the Christchurch round table is that it would be beneficial to support mechanisms for 'norm shaping' - through information instruments such as voluntary disclosure, following in the footsteps of the climate risk disclosure efforts (see the report by Keele and Coenen (2019) for a review of various policy instruments).

More broadly, most cities and regions are administered by multiple organisations with multiple levels of oversight authority for infrastructure. There are various private sector and public sector arrangements. In many countries, infrastructure is delivered by private sector organisations, constrained by commercial priorities, as well as public obligations. Changing the mindset and culture of these agencies (both private and public) remains one of the principal challenges for developing more resilient infrastructure systems.

\subsection{Policy and guidelines}

In terms of more mandatory enforcement, it is not necessarily that entirely new rules are needed, but greater enforcement of the ones that already exist. In New Zealand, for example, the Civil Defence Emergency Management Act 2002 has a general purpose to underpin the management of hazards, require coordination on civil defence matters and encourage coordination across a range of agencies. The act stipulates that a precautionary approach must be taken to the management of risk, even when there is scientific and technical uncertainty about those risks. Specifically, it requires lifeline (or critical infrastructure) utilities to 'ensure that the infrastructure is able to function to the fullest possible extent, even though this may be at a reduced level, during and after an emergency' and 'make available to the Director [of Civil Defence] in writing, on request, its plan for functioning during and after an emergency' (Civil Defence Emergency Management Act 2002: section 60). It is within the director's power to 'issue guidelines, codes, or technical standards to any person or organisation with responsibilities under this Act' (Civil Defence Emergency Management Act 2002: section 9). It does not appear to be beyond the realms of this power to require more disclosure of risk. Round-table participants with direct experience in lifeline groups have observed that this mechanism is not being enforced 
in this way but is a potential, existing, regulatory incentive for mainstreaming action. A recent study of a similar act in the state of Victoria, Australia, explains how the mandated sharing of risk information between organisations within sectors is resulting in positive outcomes through 'raising the bar' of behaviour (Naderpajouh and Matinheikki, 2019).

Further to this, more readily accessible standards and guidelines would be beneficial for 'follower' organisations. Something more may be needed, such as a regulatory push or mandatory reporting requirements to mainstream practice. The promotion of climate and natural capital reporting to broaden corporate reporting and increase the accountability of organisations to societal issues can already be observed (evidenced in the efforts of the Climate Disclosure Standards Board, as discussed by Andrew and Cortese (2013)). Key to this is helping more clearly establish the boundaries of responsibility so that infrastructure investment today (both capital and maintenance) is distributed in a way that helps establish fitness for the future. National guidance in the UK outlines that an 'all-hazard' approach is required (see Cabinet Office, 2018).

\subsection{Cross-organisational relationships}

The current lack of relationships and learning across sectors is likely to be detrimental to the future performance of critical infrastructure systems. This supports the view presented by the foresight report by Lloyd's Register Foundation (LRF, 2015), and a key motivation behind the funding of the Resilience Shift was to support learning and information sharing within and between sectors. Feedback from participants in the round-table series reinforced the value of participating in this learning and sharing process. By way of example, one participant described this experience.

The opportunity to hear from other sectors on resilience from an infrastructure perspective was something I approached with a degree

of uncertainty.... I feared I would not understand some of the technical aspects of some issues discussed and this fear was soon realised ... what I had not expected was the significant and extremely valuable learning experience this provided.

Similar observations have been made in the wider body of work produced by the Resilience Shift. It is not the role of this paper to report on that activity in detail, but the benefits of crossdisciplinary and cross-organisational engagement have formed a theme among the wider projects supported by the programme. One example is the Cape Town Day Zero initiative, which has involved the development of teaching/engagement material through filmed interviews that highlight how the crisis developed and how authorities responded. This has been designed to promote wider learning and multi-stakeholder discussions.

Cross-sector communication is not a new idea for infrastructure protection and emergency management. For example, local resilience forums in the UK have duties established within the
Civil Contingencies Act 2004 and associated regulations to plan, prepare and communicate in a multi-agency environment. The focus is on preparing for emergency response. This is similar to civil defence groups in New Zealand. However, the principle could be (and is) being taken further. Following the experience of earthquakes in Christchurch, New Zealand, round-table participants involved in managing critical infrastructure networks emphasised the value of the cross-sector networks created by civil defence groups, and other sector-specific initiatives are emerging in New Zealand for further fostering relationships and joined-up planning. Pre-existing relationships greatly enhance the ability to coordinate across organisations in the event of a crisis. However, it does not take a crisis to see the benefit of these relationships. A participant from the telecommunication sector highlighted a shift in approach from focusing on fixing problems as quickly as possible to avoidance of loss of service to more strategic planning. They described how telecommunication companies have identified vulnerabilities within their networks (highlighted by recent earthquake events) that can be better managed by coordinating with another network owner. However, the participant suggested that the need to exercise the coordination potential available through existing forums is missing and that the "big challenge is communicating with top 250 businesses - they are ones providing services to the community. [It is a] real challenge to keep up to date [with] people's expectations of possible events and failures' (participant quote). Another participant from the electricity sector described how distributors and power generation companies are working together by exploring a range of scenarios to learn about their vulnerabilities, how they might be managed and what investment should be prioritised. These are examples of multiagency forums being established not just to consider emergency response but also to inform strategic asset development and operation decisions for their assets.

The strategic and operational value in convening people from different organisations and sectors to explore infrastructure resilience was demonstrated through the process of the round tables themselves. The round-table discussions revealed areas where sectors might coordinate to challenge government investment practice, exposed where a new entity or plan may be needed to coordinate regional action and highlighted examples of best practice management.

For example, the shocks and stresses exercise (described in Section 3) helped reveal common concerns and areas of diverse views among participants. At the ports and logistics round table in London, for example, there was clear consensus that road and rail capacity was a concern for the sector. Round-table participants indicated that there was limited capacity to influence this due to the embedded economic basis of national infrastructure investment prioritising passenger movement over freight. In Berkeley, looking beyond the well-acknowledged hazard that earthquakes present for the region, climate change featured as a key concern; participants indicated limited ability to respond to that stress without greater regional coordination. The Christchurch 
round table revealed that the performance of the region's electricity distributor, Orion, through the 2010-2011 earthquake sequence had created a widely held feeling of trust in the ability of the distributor to respond to major shocks. The organisation's prior strategic planning had resulted in investment in the network that limited damage (Fenwick and Hoskin, 2011).

Figure 4 shows extracts of participant responses to demonstrate these points, focusing on responses that placed the shock or stress as a potentially high-impact event. The full response set is not reported here, as there was a significant amount of noisy data, reflecting a range of opinions over the significance of the various shocks and stresses. It was not the intention of this exercise to develop a comprehensive assessment of risk exposure, but to spark discussion around areas of agreement and disagreement in participant groups. On the whole, the exercise revealed significant disparity in initial assumptions made by participants, with only one or two clear themes emerging in the time allocated to the exercise. For example, cybersecurity-related issues such as data fraud or theft received a

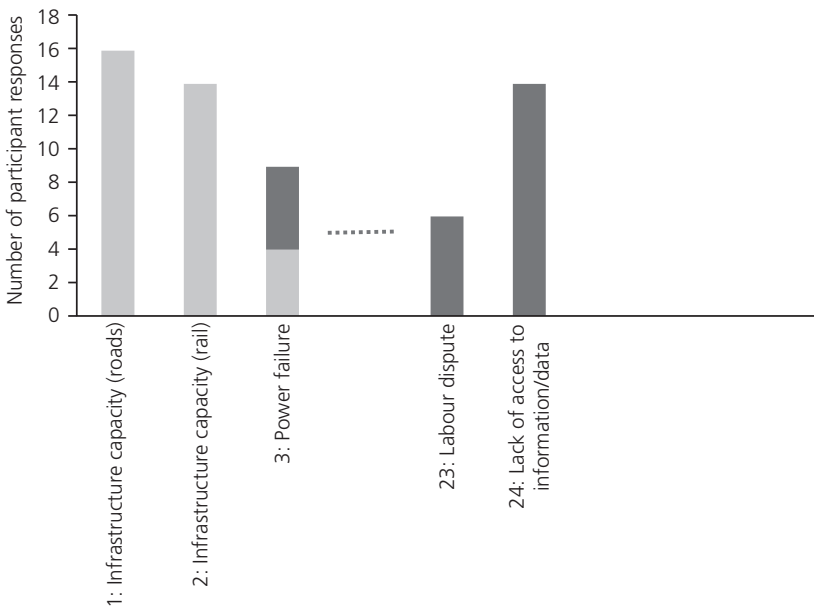

(a) mixed response with respect to possible impacts and capacity to respond. This does not mean that security issues are not relevant. Rather, in the context of the relatively open-ended nature of the discussion and the areas of focus of the participants present, this risk area did not emerge as a key theme in discussion. This may be partly due to cybersecurity being a more emerging and specialist field. Related to this point is that some participants highlighted the challenge of responding in the absence of more specific scenarios, which are a recognised way of exploring risk. However, the more open-ended nature of this exercise allowed for more emergence in what was learnt from the process.

\subsection{Data and information sharing}

Availability of data and changing use of data are also critical factors in influencing how decisions are made in managing assets for a range of scenarios. There are increasing capabilities to gather and analyse data on a wider scale to provide greater insight into system performance, but the data are often not easily extractable for timely analysis. This issue may not be a priority in

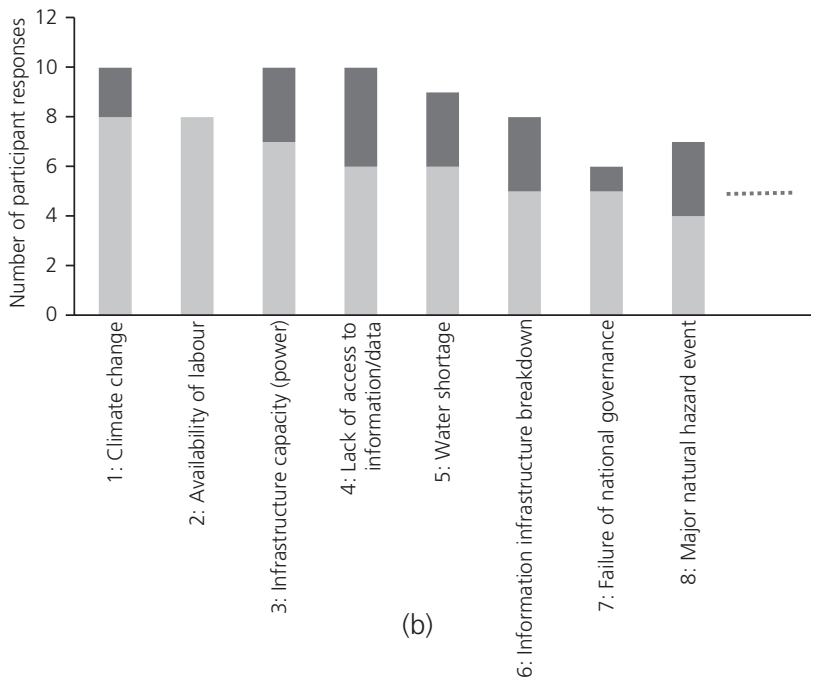

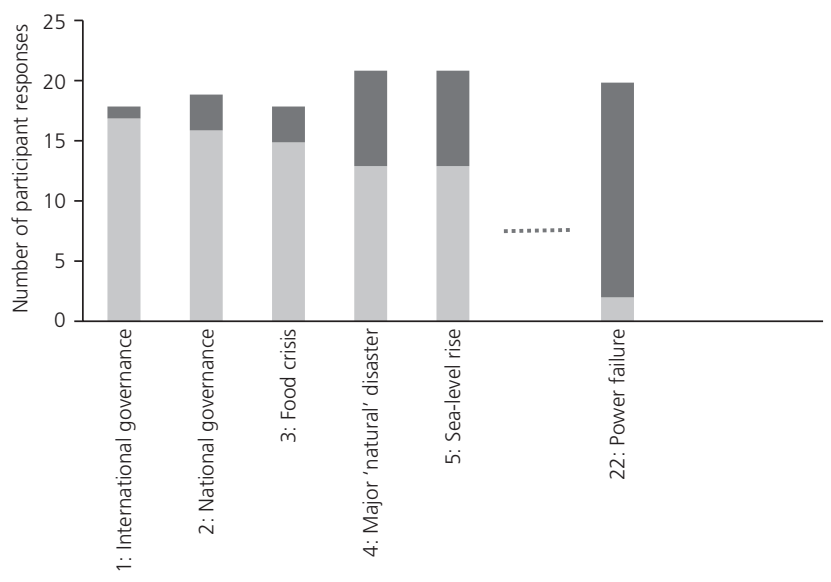

(c)

Figure 4. Example of participant responses, focusing on responses identifying 'high impact' (light grey, low capacity to respond; dark grey, high capacity to respond), listed according to agreement with 'low capacity to respond': (a) London round table; (b) Berkeley round table; (c) Christchurch round table 
business-as-usual operations, but major disruption brings this into sharp focus (Blake et al., 2019). Note also that modelling tools from engineering disciplines predominantly focus on information related to physical infrastructure systems, often excluding the influence of governance and needs of the communities themselves. The direct function of infrastructure needs to be considered in the wide socio-technical context within which it operates, suggesting a need for cross-disciplinary work. As summarised by a participant at the round table in Christchurch

\footnotetext{
... we don't have these serious conversations with the community around level of service, whole of life, and what you are prepared to invest in.... In my career I haven't seen those debates happen very often.... But increasingly across societies (communities) are looking for consistency. There is a real challenge - let alone the challenges of matching up financing systems in your own business - with the GIS system with whatever is happening on the ground. That 'supply chain of data' for decision makers - it's a major problem.
}

This emphasises the responsibility of engineers not just to design solutions but also to communicate risks and assumptions associated with different options. It also refers to financing constraints. This issue was raised in various forms during the round-table discussion. In London, for example, the prioritisation of investment into passenger infrastructure was highlighted. In Berkeley, there was interest in how financing might be arranged to support more systemic investment in resilience. In Christchurch, rules associated with various forms of funding from government and insurance sources shaped available reconstruction options. Clearly, the participation of financiers and insurers in these conversations would be beneficial in advancing the resilience agenda in engineering.

Perhaps the most challenging point of all is that public/community expectations should be considered in advancing the resilience agenda. A mismatch between what communities now expect of infrastructure services (continued service) and the reality of what might be provided following shocks creates vulnerability. While utility providers are working on strategies that are focused on increasing reliability, there is generally limited dialogue with communities with respect to acceptability of risk and how limited investment funds should be allocated to manage these risks (where considering future risk requires thinking more about future costs rather than just capital cost). The acceptability of current design standards was questioned several times during the round-table discussions. This is with respect to not just whether the standards are set at the right level but also whether these levels are acceptable to communities. As one participant described in their feedback following the city-scale modelling round table in Berkeley

[w] continue to build the same way without serious consideration for resiliency [because] on average we are still content with life safety objectives. This is no longer sufficient for a resilient community. The public needs to know that [fact] in the right way (not to scare but also not to mislead) so pressure can be put on decision makers to take resiliency more seriously in terms of resources allocation.

\section{Conclusion}

The discussions in this round-table series have helped establish current best practice in resilience thinking in infrastructure organisations and identify possible opportunities for wider change in practice. Follow-up discussions with some participants have indicated that these round tables have helped build relationships and catalyse further initiatives. However, achieving the desired outcomes explored in this paper will require a process of change and commitment on behalf of those involved to continue to push the agenda and engage with cross-organisational initiatives.

The intention of this paper is to help advance the application of resilience thinking in engineering practice. It explores how industry best practice is evolving. Lack of strategic oversight to coordinate response to resilience is a core barrier to the coordination of resilience thinking across organisations, but there is strategic and operational value in convening people from different organisations and sectors to explore infrastructure resilience.

Operationalising resilience is not mainstream in infrastructureowner organisations. Framing of cost-related considerations is critical in responding to this. Also, the availability of data and the changing use of data are critical factors in influencing how decisions get made.

There is growing support for and practice of infrastructure planning and management that involves an all-hazard analysis. Connected to this is the support for multi-stakeholder and cross-sector forums for sharing perspectives and information, with evidence of some organisations already adopting this approach. This calls for more onus to be placed in developing and maintaining multi-agency forums in non-emergency circumstances so that they become part of ordinary working habits that inform planning and investment decisions. The round tables described in this paper proved to be one means for doing that. Finally, public/community expectations should be incorporated into advancing an agenda for infrastructure resilience. This requires raising public awareness around the need for investment.

\section{Acknowledgements}

The authors thank all the round-table participants for their contributions and generosity with their time in preparing for and participating in the round tables. The round tables were run as a project under the Resilience Shift, which is supported by Lloyd's Register Foundation and Arup.

\section{REFERENCES}

Alexander D (2013) An evaluation of medium-term recovery processes after the 6 April 2009 earthquake in L'Aquila, Central Italy. Environmental Hazards 12(1): 60-73, https://doi.org/10.1080/17477891.2012.689250. Andrew J and Cortese C (2013) Free market environmentalism and the neoliberal project: the case of the Climate Disclosure Standards Board. Critical Perspectives on Accounting 24(6): 397-409, http://doi.org/10. 1016/j.cpa.2013.05.010.

Barber R and Golden J (2012) There's more to life than earthquakes; there's also tsunami, flood and wildfire to consider - practical application for 
disaster resilience. Proceedings of the 2012 Water New Zealand Annual Conference and Expo, Rotorua, New Zealand.

Blake DM, Stevenson J, Wotherspoon L, Ivory V and Trotter M (2019) The role of data and information exchanges in transport system disaster recovery: a New Zealand case study. International Journal of Disaster Risk Reduction 39: article 101124, https://doi.org/10.1016/j. ijdrr.2019.101124.

Bruneau M, Chang SE, Eguchi RT et al. (2003) A framework to quantitatively assess and enhance the seismic resilience of communities. Earthquake Spectra 19(4): 733-752, https://doi.org/10. $1193 / 1.1623497$

Cabinet Office (2018) Public Summary of Sector Security and Resilience Plans. Cabinet Office, London, UK. See https://assets.publishing. service.gov.uk/government/uploads/system/uploads/attachment data/ file/786206/20190215_PublicSummaryOfSectorSecurityAndResilience Plans2018.pdf (accessed 01/03/2020).

Civil Contingencies Act 2004. Chapter 36. Her Majesty's Stationery Office, London, UK.

Civil Defence Emergency Management Act 2002. Public Act 2002 No. 33. New Zealand Parliament, Wellington, New Zealand. See http://www. legislation.govt.nz/act/public/2002/0033/51.0/DLM150596.html (accessed 14/03/2020)

Davis CA (2015) Implementing a water system seismic resilience and sustainability program in Los Angeles. Proceedings of the 9th US-Japan-Taiwan Workshop on Water System Seismic Practices, Sendai, Japan, pp. 59-70.

Fenwick T and Hoskin K (2011) Resilience Lessons: Orion's 2010 and 2011 Earthquake Experience Independent Report. Kestrel Group, Wellington, New Zealand. See https://www.eqrecoverylearning.org/ assets/downloads/res2067-resilience-lessons-orions-earthquakeexperience.pdf (accessed 14/03/2020)

Green A and Chmutina K (2019) Building climate resilience of UK's rail network through a multihazard approach. Proceedings of the Institution of Civil Engineers - Engineering Sustainability 172(8) 450-458, https://doi.org/10.1680/jensu.18.00031.

Hargreaves AJ, Rogers CDF and Cavada M (2020) Briefing: Engineering for the far future: rethinking the value proposition. Proceedings of the Institute of Civil Engineers - Engineering Sustainability 173(1): 3-7, https://doi.org/10.1680/jensu.19.00020.

Hasan S and Foliente G (2015) Modeling infrastructure system interdependencies and socioeconomic impacts of failure in extreme events: emerging R\&D challenges. Natural Hazards 78(3): 2143-2168, https://doi.org/10.1007/s11069-015-1814-7.

Holling CS (1973) Resilience and stability of ecological systems. Annual Review of Ecology and Systematics 4: 1-23, https://doi.org/10.1146/ annurev.es.04.110173.000245.

Hollnagel E, Woods DD and Leveson N (eds) (2006) Resilience Engineering Concepts and Precepts. CRC Press, Boca Raton, FL, USA.

Hosseini S, Barker K and Ramirez-Marquez JE (2016) A review of definitions and measures of system resilience. Reliability Engineering \& System Safety 145: 47-61, https://doi.org/10.1016/j.ress.2015.08.006.

Keele S and Coenen L (2019) The Role of Public Policy in Critical Infrastructure Resilience. Resilience Shift, London, UK. See https:// www.resilienceshift.org/ (accessed 24/04/2020).

LRF (Lloyd's Register Foundation) (2015) Foresight Review of Resilience Engineering. LRF, London, UK. See http://www.webstore.lr.org/ products/3929-foresight-review-of-resilience-engineering.aspx (accessed 01/03/2020)

Miller JD and Hutchins M (2017) The impacts of urbanisation and climate change on urban flooding and urban water quality: a review of the evidence concerning the United Kingdom. Journal of Hydrology: Regional Studies 12: 345-362, https://doi.org/10.1016/j.ejrh.2017.06.006. Naderpajouh N and Matinheikki J (2019) The Role of Legislation in Critical Infrastructure Resilience. Resilience Shift, London, UK. See https://www.resilienceshift.org/ (accessed 01/03/2020).
O'Brien S and MacAskill K (2019) Infrastructure system management understanding and advancements in the methods and approaches for interdependency analysis. Proceedings of 2nd International Conference on Natural Hazards \& Infrastructure, Chania, Greece.

Park J, Seager TP, Rao PSC, Convertino M and Linkov I (2013) Integrating risk and resilience approaches to catastrophe management in engineering systems. Risk Analysis 33(3): 356-367, https://doi.org/10 1111/j.1539-6924.2012.01885.x.

Resilience Shift (2019a) Round-table Series: Advanced City-scale Modelling and Simulations for Infrastructure Resilience. Resilience Shift, London, UK. See https://www.resilienceshift.org/ (accessed 01/ 03/2020).

Resilience Shift (2019b) Round-table Series: Lessons for Infrastructure Resilience from the Reconstruction of Christchurch. Resilience Shift, London, UK. See https://www.resilienceshift.org/ (accessed 01/03/ 2020).

Resilience Shift (2019c) Round-table Series: Ports and Logistics. Resilience Shift, London, UK. See https://www.resilienceshift.org/ (accessed 01/03/2020)

Resilience Shift (2020) See https://www.resilienceshift.org/ (accessed 24/04/2020)

Shaw DR, Grainger A and Achuthan K (2017) Multi-level port resilience planning in the UK: how can information sharing be made easier? Technological Forecasting and Social Change 121: 126-138, https:// doi.org/10.1016/j.techfore.2016.10.065.

Sole T (ed.) (2011) Assuring and Enduring: Fifty Years of Civic Assurance - Tested by Time and Disaster. Oratia Media Ltd, Auckland, New Zealand.

Tanner T, Bahadur A and Moench M (2017) Challenges for Resilience Policy and Practice. Overseas Development Institute, London, UK.

Walsh CL, Glendinning S, Castán-Broto V, Dewberry E and Powell M (2015) Are wildcard events on infrastructure systems opportunities for transformational change? Futures 67: 1-10, https://doi.org/10.1016/j. futures.2015.01.005.

\section{How can you contribute?}

To discuss this paper, please email up to 500 words to the editor at journals@ice.org.uk. Your contribution will be forwarded to the author(s) for a reply and, if considered appropriate by the editorial board, it will be published as discussion in a future issue of the journal.

Proceedings journals rely entirely on contributions from the civil engineering profession (and allied disciplines). Information about how to submit your paper online is available at www.icevirtuallibrary.com/page/authors, where you will also find detailed author guidelines. 